\title{
PRODUÇÃO DE SEMENTES DE Araucaria angustifolia EM PLANTIO E EM FLORESTA NATURAL NO CENTRO-SUL DO ESTADO DO PARANÁ
}

\author{
Afonso Figueiredo Filho ${ }^{1}$, Enrique Orellana ${ }^{2}$, Flávio Nascimento ${ }^{2}$, Andrea Nogueira Dias ${ }^{3}$, \\ Mário Takao Inoue ${ }^{1}$ \\ ${ }^{1}$ Eng. Florestal. Dr., Depto. de Engenharia Florestal, UNICENTRO, Irati, Paraná, Brasil - afig@ufpr.br; takao@ irati.unicentro.br \\ ${ }^{2}$ Eng. Florestal, M.Sc., Irati, Paraná, Brasil - enriqueorellana@uol.com.br; fafnascimento@ hotmail.com \\ ${ }^{3}$ Eng $^{\mathrm{a}}$. Florestal. Dr ${ }^{\mathrm{a}}$., Depto. de Engenharia Florestal, UNICENTRO, Irati, Paraná, Brasil - andias @ irati.unicentro.br
}

Recebido para publicação: 30/10/2009 - Aceito para publicação: 30/05/2010

\begin{abstract}
Resumo
A produção de pinhões foi avaliada e comparada entre um plantio de Araucaria angustifolia (Bert.) O. Ktze. com 60 anos de idade e árvores de ocorrência natural de um fragmento de Floresta Ombrófila Mista em estágio avançado de sucessão, localizada na Floresta Nacional de Irati, estado do Paraná. Foram coletados estróbilos femininos de 27 árvores na floresta e 24 no plantio florestal, distribuídas em classes diamétricas, tendo sido ainda contados todos os estróbilos existentes em cada árvore. Para cada pinha foram coletados dados referentes ao peso, diâmetro, número e peso dos pinhões. Empregou-se o teste t para comparar ambas as tipologias mencionadas, analisando-se as seguintes variáveis: número de pinhas por árvore, número e peso de pinhões por estróbilo, número de estróbilos por classe diamétrica e a produção de sementes por hectare. A produção por árvore foi maior na floresta e a produção de sementes por hectare foi maior no plantio florestal. A produção de estróbilos por classe diamétrica apresentou valores próximos entre as duas tipologias florestais e dentro de cada classe a variabilidade encontrada foi alta. Características morfológicas das pinhas e sementes, como diâmetro, peso, número de pinhões por estróbilo e peso unitário do pinhão, apresentaram maiores valores médios na floresta.

Palavras-chave: Produção de estróbilos; floresta com araucária; plantação de araucária; pinhão de araucária.
\end{abstract}

\begin{abstract}
Seed production of Araucaria angustifolia in plantation and in natural forest at Central-South of the Parana State. Seed production was evaluated and compared between a plantation of Araucaria angustifolia with 60 years old and trees of natural occurrence in a Mixed Ombrophyllous Forest fragment in an advanced stage of succession, located at Irati National Forest, Parana State. Females strobilus were collected from 27 trees in natural forest and 24 trees of the Araucaria plantation, distributed in diameter classes, even the whole number of strobilus were counted in each tree. For each strobilus was collected data of weight, diameter, number and weight of the seeds. Student's $\mathbf{t}$ test was used to compare both typologies mentioned analyzing the following variables: number of strobilus per tree, number and weight of seeds per strobilus, number of strobilus in each dbh class and production of seeds per hectare. The production per tree was higher in natural forest and seed production per hectare was higher in Araucaria plantation. The production of strobilus per dbh class showed similar values between the two forest typologies and in each class, the variability found was high. Morphological characteristics of the strobilus and seeds such as: diameter, weight, number of seeds per strobilus and unit weight of the seed had higher mean values in the natural forest.

Keywords: Strobilus production; araucaria forest; araucaria plantation; araucaria seeds.
\end{abstract}

\section{INTRODUÇÃO}

Araucaria angustifolia (Bert.) O. Ktze. é a única espécie de seu gênero com ocorrência natural no Brasil. Os maiores povoamentos estão concentrados nos estados do Sul, nos planaltos, onde predominam temperaturas baixas, chuvas abundantes e bem distribuídas (SHIMIZU; OLIVEIRA, 1981). 
Essa espécie está presente na formação florestal conhecida como Floresta Ombrófila Mista, ou Floresta com Araucária. Segundo Santos et al. (2002), a floresta das araucárias é uma fonte de inúmeros subprodutos florestais, tanto madeiráveis como não madeiráveis. Dentre os não madeiráveis, esses autores citam o pinhão, semente da Araucaria angustifolia, como um alimento nutritivo apreciado pela fauna silvestre e pelo homem.

A espécie, principal gimnosperma do Brasil, foi desordenadamente explorada nas últimas décadas, para comercialização da madeira, considerada de boa qualidade para fabricação de móveis e construção civil, bem como para a produção de papel e celulose. Segundo Stefenon et al. (2003), na década de 70 , a araucária correspondia a $90 \%$ de cerca de um milhão de metros cúbicos de madeira exportada pelo país.

Essa exploração desenfreada levou a espécie a ser inserida na lista oficial de espécies da flora brasileira ameaçadas de extinção do Instituo Brasileiro do Meio Ambiente e dos Recursos Naturais Renováveis (IBAMA), em 1992. Em 2001, uma resolução do Conselho Nacional do Meio Ambiente (CONAMA) suspendeu o corte e a exploração das espécies que constam na lista oficial do IBAMA em populações naturais.

Desse modo, o pequeno produtor rural buscou a comercialização de produtos não madeiráveis para várias espécies florestais ameaçadas de extinção como uma alternativa para obter renda extra. É o caso do pinhão produzido pela araucária. A cultura monoespecífica de araucária foi uma maneira que o produtor rural encontrou para "driblar" as restrições impostas pela legislação e usufruir das qualidades que a espécie oferece.

O pinheiro permanece mais de 200 anos em produção (MATTOS, 1972). Nos primeiros anos, a produção de pinhão é pequena e, mesmo quando atinge a plena produção, as safras são cíclicas. Durante dois ou três anos produz abundantemente, reduzindo a produção posteriormente, de forma gradativa, nos dois ou três anos seguintes (MATTOS, 1994). Segundo Carvalho (1994), árvores plantadas isoladas iniciam a produção de pinhões entre 10 e 15 anos, porém em povoamentos a produção dá-se a partir de 20 anos de idade. Estudos conduzidos por Bandel; Gurgel (1967), para determinar a proporção de indivíduos machos e fêmeas de araucária em algumas florestas naturais no Sul do Brasil e em plantios homogêneos, encontraram a proporção de 52,4\% para machos e 47,6\% para fêmeas. Carvalho (1994) afirmou que o pinheiro brasileiro produz anualmente cerca de 40 pinhas, chegando a atingir até 200 pinhas por planta.

Estudos que visem a produção de pinhões podem ser uma ferramenta importante para promover a extensão rural, com o intuito de trazer alternativas para que o pequeno produtor tenha outras fontes de renda. Entretanto muitos dos estudos que envolvem a araucária foram desenvolvidos visando técnicas de manejo principalmente para produção de madeira. Um estudo realizado por Guerra et al. (2002), citado por Silva (2006), demonstra que a renda total corrigida para a exploração do pinhão seria $22 \%$ maior que a renda obtida num sistema de exploração de madeira, indicando, para Savana Parque, que a exploração dos pinhões em longo prazo é mais rentável que a exploração da madeira, ao mesmo tempo reduzindo a pressão de corte sobre os relictos existentes.

O objetivo deste trabalho foi testar as seguintes hipóteses:

a) A produção de sementes por árvore é diferente em árvores de Araucaria angustifolia crescendo em floresta e em plantios florestais.

b) As características dos estróbilos e das sementes diferem em árvores de Araucaria angustifolia crescendo em floresta e em plantios florestais.

\section{MATERIAIS E MÉTODOS}

\section{Área de estudo}

A pesquisa foi realizada em dois experimentos com parcelas permanentes instalados na Floresta Nacional de Irati, localizada nos municípios de Irati e Fernandes Pinheiro, estado do Paraná. O primeiro, com 25 ha (25 blocos de um ha cada), foi instalado em 2000-01, em um fragmento de Floresta Ombrófila Mista (FOM) com área de 1.272,9 ha. O segundo, com 10 ha (10 blocos de um ha cada), foi instalado em 2004-05, em talhões plantados há 60 anos com Araucaria angustifolia. Todas as árvores com diâmetros a $1,3 \mathrm{~m}$ (DAP) $\geq 10 \mathrm{~cm}$ têm sido medidas a cada 3 anos, identificadas, numeradas e posicionadas em um sistema cartesiano $(\mathrm{X}, \mathrm{Y})$. 
O clima da região é $\mathrm{Cfb}$, segundo a classificação de Köppen, com precipitação média anual de $1442 \mathrm{~mm}$ e sem estação seca. A temperatura média em janeiro é de $22{ }^{\circ} \mathrm{C}$, e a de julho fica em torno de $10^{\circ} \mathrm{C}$, com mais de cinco geadas por ano. O relevo local é considerado de ondulado a plano. $\mathrm{O}$ solo, classificado como Argissolo vermelho-amarelo, apresenta acidez média (DISPERATI, 2007).

\section{Coleta dos dados}

A coleta dos estróbilos (pinhas) foi realizada nos meses de abril e maio de 2008, época em que eles estavam em pleno desenvolvimento. As árvores amostradas foram selecionadas buscando-se contemplar a distribuição diamétrica da Araucaria angustifolia existente nas duas populações, plantio com Araucaria angustifolia e o remanescente com Floresta Ombrófila Mista.

Na tabela 1 pode-se observar o número de árvores amostradas e a quantidade de pinhas (estróbilos) coletada em cada classe de DAP com amplitude de $10 \mathrm{~cm}$. A coleta das pinhas em cada árvore e a contagem de todas as pinhas existentes relativas à safra 2008 exigiu a subida até a copa das árvores, por meio do uso de técnicas de escalada.

A princípio, buscou-se coletar três pinhas de cada árvore-amostra, porém, em campo, verificouse que, na floresta, as árvores pertencentes à classe inferior $(20-30 \mathrm{~cm})$ apresentavam poucos indivíduos em fase de reprodução, e quando estavam produzindo, encontravam-se, em alguns casos, apenas 1 ou 2 estróbilos. Em algumas árvores foram coletados até 4 estróbilos. Evidentemente, tendo em vista que as duas populações apresentavam distribuição diamétrica diferenciada, não foi possível encontrar no plantio de araucária indivíduos na primeira e na última classe diamétrica. Desse modo, na floresta foram coletados 79 estróbilos em 27 árvores, enquanto que no plantio foram extraídos 70 estróbilos em 24 árvores, que foram agrupados em classes de DAP conforme mostra a tabela 3.

Tabela 1. Número de árvores-amostra e estróbilos amostrados por classe diamétrica nas duas tipologias florestais.

Table 1. Number of sample-trees and strobilus collected per diameter (dbh) classes in both forest typologies.

\begin{tabular}{lcccc}
\hline \multirow{2}{*}{$\begin{array}{l}\text { Centro de classe } \\
(\mathbf{c m})\end{array}$} & \multicolumn{2}{c}{ Plantio com araucária } & \multicolumn{2}{c}{ Floresta Ombrófila Mista } \\
\cline { 2 - 5 } & $\mathbf{N}^{\mathbf{0}}$ de árvores-amostra & $\begin{array}{c}\mathbf{N}^{\mathbf{0}} \mathbf{d e} \\
\text { estróbilos }\end{array}$ & $\mathbf{N}^{\mathbf{0}}$ de árvores-amostra & $\mathbf{N}^{\mathbf{0}}$ de estróbilos \\
\hline 25 & 0 & - & 2 & 2 \\
35 & 8 & 20 & 5 & 14 \\
45 & 6 & 19 & 5 & 15 \\
55 & 6 & 19 & 5 & 16 \\
65 & 4 & 12 & 5 & 15 \\
75 & 0 & - & 5 & 79 \\
\hline Total & 24 & 70 & 27 & \\
\hline
\end{tabular}

\section{Procedimentos realizados em laboratório}

As 149 pinhas foram pesadas (peso verde) em balança digital e os diâmetros e comprimentos das pinhas foram medidos com o auxílio de uma suta. As pinhas foram submetidas à câmara seca, com ventilação forçada, por cerca de 2 semanas, até atingirem uma coloração e com condições de permitir a extração dos pinhões. Em seguida foram pesadas e abertas. Os pinhões chochos (estéreis) foram descartados e os pinhões desenvolvidos (fecundados) foram contados e pesados em balança digital.

Os estudos comparativos entre as tipologias florestais envolveram número de pinhas por árvore, número e peso de pinhões por estróbilo, número de estróbilos por classe diamétrica e produção de sementes por hectare. Para essas análises, foi utilizado o "teste t", em que cada uma das tipologias foi considerada como um tratamento, testando-se as seguintes hipóteses:

$\mathrm{H}_{0} \quad$ A produção de sementes por árvore média é igual em árvores de Araucaria angustifolia crescendo em floresta e em plantios florestais.

$\mathrm{H}_{1}$ A produção de sementes por árvore média é diferente em árvores de Araucaria angustifolia crescendo em floresta e em plantios florestais.

$\mathrm{H}_{0} \quad$ As características dos estróbilos e das sementes são iguais em árvores de Araucaria angustifolia crescendo em floresta e em plantios florestais 
$\mathrm{H}_{1} \quad$ As características dos estróbilos e das sementes diferem em árvores de Araucaria angustifolia crescendo em floresta e em plantios florestais. (2004):

A produção de sementes foi estimada conforme metodologia proposta por Mantovani et al.

$$
\mathrm{PS}=\mathrm{N} \cdot \mathrm{Ne} \cdot \mathrm{Mp}
$$

Em que: $\mathrm{PS}=$ produção de sementes $(\mathrm{kg} / \mathrm{ha})$;

$\mathrm{N}=$ número de plantas femininas por hectare;

$\mathrm{Ne}=$ número médio de estróbilos por planta;

$\mathrm{Mp}=$ massa média de pinhões por estróbilo $(\mathrm{kg})$.

A definição da proporção macho/fêmea nas duas tipologias florestais foi definida com base no valor médio da proporcionalidade dos sexos da espécie encontrados por Silva (2006) e Bandel; Gurgel (1967). O primeiro autor, em trabalho realizado em um plantio de araucária, amostrou 48 árvores quanto ao sexo, determinando que 22 árvores eram femininas (45,8\%) e 26 masculinas $(54,2 \%)$, enquanto que na área de ocorrência natural de 54 indivíduos analisados, 26 eram femininos $(48,2 \%)$ e 28 masculinos $(51,8 \%)$. Por outro lado, Bandel; Gurgel (1967), em um estudo específico para definir a proporcionalidade de plantas masculinas e femininas (dioicia), encontraram que a proporção de plantas masculinas foi de $52,4 \%$ e a das plantas femininas de $47,6 \%$, tanto em plantios monoespecíficos como em árvores de ocorrência natural. Assim sendo, nesta pesquisa, adotaram-se valores médios desses dois trabalhos, ou seja, $46,7 \%$ e 47,9\%, respectivamente, para a plantação de araucária e para as árvores da floresta.

\section{RESULTADOS E DISCUSSÃO}

\section{Proporcionalidade entre fêmeas e machos}

Os dados referentes ao número de araucárias e o percentual de indivíduos femininos em cada uma das áreas de estudo estão apresentados na tabela 2.

Tabela 2. Número e proporção de plantas fêmeas nas duas áreas pesquisadas.

Table 2. Number and proportion of female trees in both studied areas.

\begin{tabular}{llccccc}
\hline Tipologia & Área (ha) & $\begin{array}{c}\text { Número de } \\
\text { araucárias }\end{array}$ & $\begin{array}{c}\text { Número de } \\
\text { araucárias/ha }\end{array}$ & $\begin{array}{c}\text { Número de } \\
\text { fêmeas }\end{array}$ & $\begin{array}{c}\text { Número de } \\
\text { fêmeas/ha }\end{array}$ & $\begin{array}{c}\text { \% de } \\
\text { fêmeas }\end{array}$ \\
\hline Natural & 25 & 1062 & 42,48 & 508,70 & 20,34 & 47,90 \\
Plantada & 10 & 2762 & 276,20 & 1289,85 & 128,98 & 46,70 \\
\hline
\end{tabular}

A densidade de indivíduos adultos por hectare foi de 42,5 e 276,2 árvores/ha, respectivamente, para o remanescente de Floresta Ombrófila Mista e para o plantio de araucária, com base na listagem completa das duas amostras. Silva (2006), em um estudo semelhante a este, comparou a produção de sementes de um fragmento de Floresta Ombrófila Mista na Reserva Genética Florestal de Caçador e em um plantio de araucária implantado em 1958 na FLONA de Caçador, na safra de 2005, encontrando 29,5 e 208,7 árvores/ha na floresta natural e plantada, respectivamente.

\section{Características e produção média de estróbilos por árvore}

Foram encontradas as médias por árvore de 20,48 e 9,79 estróbilos, 78,92 e 54,47 sementes por estróbilos e um peso médio de pinhões por estróbilo de 556,28 e 375,48 g, respectivamente, para a floresta natural e a plantada. $\mathrm{O}$ teste $\mathrm{t}$ indicou diferenças significativas entre essas médias (Tabela 3 ).

Conforme se pode observar na tabela 4, Mantovani et al. (2004), em um fragmento de Floresta Ombrófila Mista no Parque Estadual Campos do Jordão, estado de São Paulo, encontraram 13 em 2001 e 19,5 estróbilos/planta em 2002. Em algumas fazendas do planalto de Santa Catarina, em áreas de remanescentes da FOM, foram determinadas, em média, 20 pinhas por ano por planta (BRDE, 2005). Silva (2006) encontrou em média 5,6 estróbilos por árvore na floresta e 1,39 no plantio, com 47 anos de idade. 
Tabela 3. Valores médios das variáveis utilizadas para estimativa da produção de sementes nas duas tipologias.

Table 3. Mean values of variables used to estimate the production of araucaria seeds in both typologies.

\begin{tabular}{lccc}
\hline Tipologia & $\begin{array}{c}\text { Número médio de } \\
\text { estróbilos por planta }\end{array}$ & $\begin{array}{c}\text { Número médio de sementes } \\
\text { por estróbilo }\end{array}$ & $\begin{array}{c}\text { Peso médio de pinhões por } \\
\text { estróbilo (g) }\end{array}$ \\
\hline Floresta & 20,48 & 78,92 & 556,28 \\
Plantada & 9,79 & 54,47 & 375,48 \\
Teste t & $2,36 *(p=0,02235)$ & $3,94 * *(p=0,000127)$ & $3,5 * *(p=0,00066)$ \\
\hline *significativo ao nível de $2 \%$ de probabilidade. ** significativo ao nível de $0,01 \%$ de probabilidade.
\end{tabular}

Tabela 4. Dados advindos de pesquisas sobre o tema estudado.

Table 4. Data from researches about the studied topic.

\begin{tabular}{|c|c|c|c|c|c|c|c|}
\hline \multirow{3}{*}{ Variáveis } & \multicolumn{2}{|c|}{ (1) } & \multicolumn{2}{|c|}{ (2) } & \multirow{2}{*}{\multicolumn{2}{|c|}{$\frac{(3)}{\text { Floresta }}$}} & \multirow{3}{*}{$\frac{(4)}{(*)}$} \\
\hline & \multirow{2}{*}{ Floresta } & \multirow{2}{*}{ Plantada } & \multirow{2}{*}{ Floresta } & \multirow{2}{*}{ Plantada } & & & \\
\hline & & & & & 2001 & 2002 & \\
\hline $\begin{array}{l}\mathrm{N}^{\circ} . \text { médio de estróbilos por } \\
\text { planta }\end{array}$ & 20,48 & 9,79 & 5,6 & 1,3 & 13 & 19,5 & - \\
\hline $\begin{array}{l}\text { Peso médio dos estróbilos } \\
(\mathrm{kg})\end{array}$ & 1,850 & 1,390 & 1,48 & 0,733 & - & - & 1,766 \\
\hline $\begin{array}{l}\text { Peso médio de pinhões por } \\
\text { estróbilo }(\mathrm{g})\end{array}$ & 556,28 & 375,48 & 418 & 200 & - & - & 583,27 \\
\hline $\begin{array}{l}\text { Diâmetro médio das pinhas } \\
(\mathrm{cm})\end{array}$ & 15,1 & 13,7 & 14,3 & 12,4 & - & - & $48,57(* *)$ \\
\hline Peso unitário do pinhão (g) & 7,57 & 5,8 & 7,0 & 5,0 & 6,58 & - & - \\
\hline $\mathrm{N}^{\mathrm{o}}$. de pinhões por estróbilo & 78,9 & 54,47 & 56,9 & 39,4 & 93,9 & 80,7 & 70,51 \\
\hline $\begin{array}{l}\% \text { do peso de sementes } \\
\text { fecundadas em relaçãa às } \\
\text { chochas }\end{array}$ & $28,88 \%$ & $22,6 \%$ & $28,3 \%$ & $27,3 \%$ & - & $41,8 \%$ & - \\
\hline $\begin{array}{l}\text { Produção de pinhões por ha } \\
\text { (kg/ha) }\end{array}$ & 222,39 & 466,70 & 44,3 & 24,6 & 117 & 160 & - \\
\hline
\end{tabular}

$\mathrm{Na}$ floresta, as pinhas apresentaram em média $1,850 \mathrm{~kg}$ - a menor apresentou $0,718 \mathrm{~kg}$ e a maior $3,9 \mathrm{~kg}$. No plantio florestal, a média foi $1,390 \mathrm{~kg}-$ a menor apresentou $0,421 \mathrm{~kg}$ e a maior $2,7 \mathrm{~kg}$. Silva (2006), em seu estudo, determinou 1,48 e $0,733 \mathrm{~kg}$, respectivamente para as pinhas oriundas de árvores em ocorrência natural e em plantios homogêneos. Vernalha et al. (1972) avaliaram 414 pinhas coletadas no município de Curitiba, estado do Paraná (não especifica se são árvores nativas ou plantadas) e determinaram que o peso médio dos estróbilos era de $1,766 \mathrm{~kg}$.

O diâmetro médio das pinhas, na floresta, foi de $15,1 \mathrm{~cm}$, variando de $11,1 \mathrm{a} 19,2 \mathrm{~cm}$, enquanto que na plantada o diâmetro médio foi $13,7 \mathrm{~cm}$, variando de 10,6 a 17,1 cm. Silva (2006) encontrou média de 12,4 cm de diâmetro no plantio e 14,3 cm na Floresta.

$\mathrm{Na}$ floresta, $28,88 \%$ do peso verde médio dos estróbilos eram compostos por sementes bem formadas (fecundadas) quando comparadas à presença de pinhões chochos. No plantio florestal, 22,6\% . Mantovani et al. (2004) encontraram, em média, 41,8\% em remanescentes de Floresta Ombrófila Mista. Silva (2006) encontrou 27,3\% nas florestas plantadas e 28,3\% em pinhas oriundas de árvores de ocorrência natural.

A tabela 3 indica que a floresta produziu um número maior de estróbilos e estes possuem um número maior de pinhões em comparação com o plantio. Uma hipótese para isso é que as árvores de araucária em ocorrência natural normalmente estão situadas no dossel da floresta e, portanto, livre de competição de copas de outras árvores por luz, ao contrário do que acontece em um plantio homogêneo e equiâneo, onde a competição de copas acontece em todo o ciclo de vida das árvores.

Segundo Silva (2006), a alta densidade de árvores no plantio pode gerar um acentuado processo de competição intraespecífica, causando uma relação negativa muito grande entre densidade e desenvolvimento das plantas, consequentemente fazendo com que cada planta tenha uma menor produção. 


\section{Número de estróbilos por classe diamétrica}

As estatísticas do número de estróbilos das árvores amostradas distribuídas nas classes diamétricas estão apresentadas na tabela 5. Nota-se que ocorreu maior variabilidade do número de estróbilos por árvore na floresta, quando comparada ao plantio. Essa variabilidade é mais evidente na classe de $60-70 \mathrm{~cm}$ de DAP, na qual foi determinado coeficiente de variação de $113,27 \%$ na floresta e de $75,93 \%$ no plantio.

Tabela 5. Valores médio, máximo e mínimo e coeficiente de variação do número de estróbilos por árvore no plantio (Plan.) e na floresta (Nat.) em diferentes classes diamétricas.

Table 5. Mean, maximum and minimum values and coefficient of variation of the number of strobilus in the plantation and native forest on different diameter classes.

\begin{tabular}{|c|c|c|c|c|c|c|c|c|c|c|c|c|}
\hline \multirow{3}{*}{ Estatísticas } & \multicolumn{12}{|c|}{ Centro de classe $(\mathrm{cm})$} \\
\hline & \multicolumn{2}{|c|}{25} & \multicolumn{2}{|c|}{35} & \multicolumn{2}{|c|}{45} & \multicolumn{2}{|c|}{55} & \multicolumn{2}{|c|}{65} & \multicolumn{2}{|c|}{75} \\
\hline & Nat. & Plan. & Nat. & Plan. & Nat. & Plan. & Nat. & Plan. & Nat. & Plan. & Nat. & Plan. \\
\hline Média & 1 & - & 9,6 & 6,25 & 11 & 11,5 & 16,2 & 13 & 33 & 9,5 & 40,4 & - \\
\hline Máximo & 1 & - & 15 & 16 & 19 & 21 & 23 & 29 & 79 & 18 & 73 & - \\
\hline Mínimo & 1 & - & 1 & 1 & 6 & 3 & 6 & 7 & 4 & 6 & 12 & - \\
\hline CV\% & - & - & 85,4 & 59,6 & 104,4 & 61,6 & 103,8 & 69,1 & 113,2 & 75,9 & 99,2 & - \\
\hline
\end{tabular}

Observa-se, na tabela 5 e na figura 1, uma produção maior de estróbilos na medida em que o DAP aumenta, exceto para a classe maior $(\mathrm{DAP}=65 \mathrm{~cm}$ ) do plantio de araucária. Nessa classe, constatase grande diferença entre as duas tipologias estudadas, ao contrário do observado nas demais classes. Provavelmente as quatro árvores amostradas nessa classe não foram capazes de representá-la adequadamente.

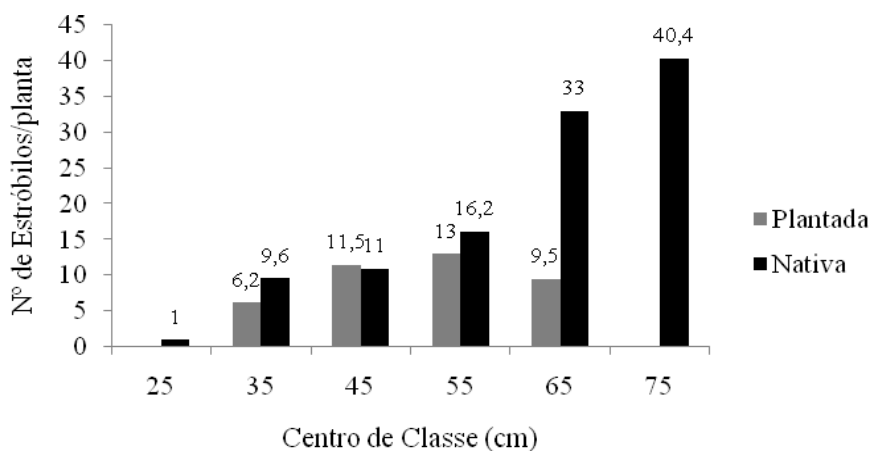

Figura 1. Número médio de estróbilos por árvore nas classes diamétricas.

Figure 1. Mean number of strobilus per tree in the diameter classes.

\section{Características e produção dos pinhões por árvore}

A produção média de pinhões por árvore na floresta foi de $11,39 \mathrm{~kg}$, aproximadamente 3 vezes maior que no plantio florestal, que teve uma produção média de $3,76 \mathrm{~kg}$. Isso sugere que árvores mais antigas e com copas maiores são capazes de produzir mais pinhões. No entanto a produção por unidade de área é maior no plantio, considerando que o mesmo tem uma maior quantidade de árvores por hectare.

Foram encontradas, em média, 78,9 sementes por estróbilo na floresta, enquanto que no plantio florestal ocorreram em média 54,47 sementes por estróbilo. Mantovani et al. (2004) encontraram, em uma floresta no estado de São Paulo, 93,9 e 80,7 sementes em 2001 e 2002, respectivamente.

O peso unitário de cada pinhão na floresta foi em média 7,57 g, e no plantio foi de $5,8 \mathrm{~g}$. Mantovani et al. (2004) encontraram 6,58 g e $7 \mathrm{~g}$ nos anos de 2001 e 2002, respectivamente. Silva (2006) obteve $7 \mathrm{~g}$ em média na floresta e $5 \mathrm{~g}$ no plantio florestal. Anselmini (2005), em seu estudo, determinou que os menores pinhões apresentaram uma massa média de 2,80 g nas pinhas de ramos secundários, e os maiores pinhões uma massa média de 12,65 g para pinhões coletados nos estróbilos de ramos primários. 


\section{Produção por hectare}

A produtividade de sementes foi estimada em $231,74 \mathrm{~kg} / \mathrm{ha}$ para a floresta e $474,20 \mathrm{~kg} / \mathrm{ha}$ para o plantio florestal. Muito embora a produção média de estróbilos por árvore e o peso médio por pinhão sejam maiores na floresta, a produção por hectare no plantio é 2 vezes superior à da floresta, devido ao número de árvores por hectare maior que na floresta. Deve ser ressaltado que os percentuais de fêmeas existentes em plantios e em florestas naturais vieram de dados da literatura (47,9\% na floresta e $46,7 \%$ no plantio), conforme relatado na metodologia. É importante enfatizar que para este estudo não existem informações a respeito da procedência das sementes utilizadas no plantio florestal, para efetuar maiores inferências com relação à produção.

Silva (2006) encontrou maior produtividade de pinhões na floresta $(44,3 \mathrm{~kg} / \mathrm{ha})$ quando comparada à plantada $(24,6 \mathrm{~kg} / \mathrm{ha})$, mesmo havendo um número consideravelmente maior de fêmeas/ha no plantio florestal. Segundo o autor, a alta densidade de plantas existentes no plantio pode ter levado a uma grande competição entre indivíduos por nutrientes e luminosidade, o que pode ter acarretado uma menor produção por árvore (1,3 estróbilos/planta). Outro fator que pode ter tido influência, segundo o citado autor, é a diferença de idade entre as árvores, indicando que no plantio as árvores têm 50 anos de idade e entraram em maturação sexual havia 15 anos, e as árvores de ocorrência natural, por serem mais altas e com maior DAP, eram mais velhas, apresentando um maior número médio de estróbilos por planta $(5,6)$.

Mantovani et al. (2004) encontraram $117 \mathrm{~kg} / \mathrm{ha}$ em 2001 e $160 \mathrm{~kg} / \mathrm{ha}$ no ano seguinte, fato que comprova que a produção oscila de um ano para outro. Esse autor cita que Solórzano Filho (2001), na mesma região, estimou a produção em $427 \mathrm{~kg} / \mathrm{ha}$.

Nota-se que existe uma grande diferença na produção de pinhões por hectare, mas é preciso enfatizar que fatores como número de indivíduos por hectare, porcentagem de fêmeas e grau de evolução da floresta são determinantes na avaliação da produção de pinhões por hectare. Sousa; Hattemer (2003) citaram que a idade das árvores é um importante fator que define o período e a intensidade de florescimento, bem como frutificação.

O preço do pinhão oscila durante o ano e a cada ano, dependendo da oferta do produto. Segundo a CEASA (2009), o preço médio do pinhão em Curitiba, no ano de 2008, foi de $\mathrm{R} \$ 2,03 / \mathrm{kg}$, variando entre $\mathrm{R} \$ 1,70 / \mathrm{kg}$ e $\mathrm{R} \$ 2,50 / \mathrm{kg}$. Se o produtor rural vendesse o quilo do pinhão a $\mathrm{R} \$ 2,00$, ele iria gerar uma renda de aproximadamente $\mathrm{R} \$ 950,00 / \mathrm{ha} / \mathrm{ano}$ em um plantio homogêneo. Na floresta, a renda aproximada seria de $\mathrm{R} \$ 460,00 / \mathrm{ha} / \mathrm{ano}$

\section{CONCLUSÕES}

- A produção de sementes por árvore é maior na floresta.

- O número de estróbilos por planta, peso e o diâmetro médio dos estróbilos são maiores na floresta.

- A quantidade de sementes por estróbilo, a massa de pinhões por estróbilo e o peso unitário do pinhão são maiores na floresta.

- A produção de sementes por hectare é maior no plantio florestal.

- A produção de estróbilos é maior nas maiores classes de diâmetro na floresta. Existe essa tendência também no plantio, porém houve decréscimo de produção na última classe.

- A renda anual com a coleta de pinhões de um plantio de araucária pode ser um importante agregador de rendas ao proprietário.

- Estudos que estejam voltados à produção de pinhão podem contribuir para implementação de políticas públicas com o intuito de trazer alternativas para que o pequeno produtor rural possa contar também com essa relevante alternativa de renda.

\section{REFERÊNCIAS}

ANSELMINI, J. I. Fenologia reprodutiva da Araucaria angustifolia (Bert.) O. Ktze. na região de Curitiba, PR. 2005. 62 p. Dissertação (Mestrado em Agronomia) - Universidade Federal do Paraná.

BANDEL, G.; GURGEL, J. A. A. Proporção do sexo em Araucaria angustifolia. Silvicultura em São Paulo, São Paulo, v. 6, p. 209-220. 1967. 
BRDE - Banco Regional de Desenvolvimento do Extremo Sul, SC. Cultivo da Araucaria angustifolia: viabilidade econômico-financeira e alternativas de incentivo. Florianópolis, BRDE, 2005, 53 p.

CARVALHO, P. E. R. Araucaria angustifolia (Bertoloni) Otto Kuntze: pinheiro-do-paraná. In: CARVALHO, P. E. R. (Ed.) Espécies florestais brasileiras: recomendações silviculturais, potencialidades e uso da madeira. Colombo: EMBRAPA - CNPF; Brasília: EMBRAPA - SPI, 1994. p. $70-78$.

CEASA-PR. Central de Abastecimento do Paraná S.A. Disponível em <www.ceasa.pr.gov.br/>. Acesso em 18 maio 2009.

DISPERATI, A. A.; SANTOS, J. R.; OLIVEIRA FILHO, P. A.; NEEFF, T. Aplicação da técnica "filtragem de locais máximas" em fotografia aérea digital para a contagem de copas em reflorestamento de Pinus elliottii. Sci. For., Piracicaba, n. 76, p. 45-55, dez. 2007.

GUERRA, M. P.; SILVEIRA, V.; REIS, M. S.; SCHNEIDER, L. Exploração, manejo e conservação da araucária (Araucaria angustifolia). In: SIMÕES, L. L.; LINO, C. F. (Org.). Sustentável Mata Atlântica: a exploração de seus recursos florestais. São Paulo: Editora SENAC São Paulo, 2002. p. 85-101.

MANTOVANI, A.; MORELLATO, P. C.; REIS, M. S. Fenologia reprodutiva e produção de sementes em Araucaria angustifolia (Bert.) O. Kuntze. Brasil. Bot., v. 27, n. 4, p. 787-796, out-dez. 2004.

MATTOS, J. R. O pinheiro brasileiro. São Paulo: Grêmio Politécnico, 1972. 620 p.

O pinheiro brasileiro. 2. ed. Lajes, Santa Catarina: Artes Gráficas Princesa, 1994. 225 p.

SANTOS, A. J.; CORSO, N. M.; MARTINS, G.; BITTENCOURT, E. Aspectos produtivos e comerciais do pinhão no estado do Paraná. Revista Floresta, n. 32, v. 2, p. 163-169. 2002.

SHIMIZU, J. I.; OLIVEIRA, Y. M. M. Distribuição da variação e usos de recursos: genética de araucária no sul do Brasil. Curitiba-PR: Embrapa - URPFCS, doc. 04, 1981. 09 p.

SILVA, C. V. Aspectos da obtenção e comercialização de pinhão na região de Caçador, SC. 2006. 111 p. Dissertação (Mestrado em Recursos Genéticos Vegetais) - Universidade Federal de Santa Catarina.

SOLÓRZANO FILHO, J. A. Demografia, fenologia e ecologia da dispersão de sementes de Araucaria angustifolia (Bert.) Ktze. (Araucariaceae), numa população relictual em Campos do Jordão, SP. São Paulo, 2001, 154 f. Dissertação (Mestrado em Ciências - Área de Ecologia) - Universidade de São Paulo.

SOUSA, V. A.; HATTEMER, H. H. Fenologia reprodutiva da Araucaria angustifolia no Brasil. Bol. Pesq. Fl., Colombo, n. 47, p. 19-32, jul./dez. 2003.

STEFENON, V. M.; NODARI, R. O.; REIS, M. S. Padronização de protocolo AFLP e sua capacidade informativa para análise da diversidade genética em Araucaria angustifolia. Sci. For., n. 64, p. 163-171, dez. 2003.

VERNALHA, M. M.; LEAL, J.; GABARDO, J. C.; DA ROCHA, M. A. L.; DA SILVA, R. P. Considerações sobre a semente da Araucaria angustifolia (Bertol.) Kuntze. Acta.Biol.Par., v. 1, n. 3-4, p. 39-96. 1972. 